\title{
SPATIAL VARIABILITY OF SOIL APPARENT ELECTRICAL CONDUCTIVITY - EFFECT OF THE NUMBER OF SUBSAMPLES
}

\author{
Emanoel Di Tarso dos S. Sousa ${ }^{*}$, Daniel M. de Queiroz ${ }^{2}$, \\ Jorge T. F. Rosas ${ }^{3}$, Amélia L. do Nascimento ${ }^{1}$
}

\begin{abstract}
${ }^{1 *}$ Corresponding author. Universidade Federal Rural de Pernambuco, Departamento de Engenharia Agrícola/ Recife - PE, Brasil. E-mail: emanoel.sousa@ufrpe.br | ORCID ID: https://orcid.org/0000-0002-8290-899X
\end{abstract}

\author{
KEYWORDS \\ Kriging, Soil \\ sampling, Spatial \\ variability pattern, \\ Soil sensors.
}

\begin{abstract}
Soil apparent electrical conductivity (ECa) sensors have been used to detect spatial variability because they correlate with soil attributes. Studies with soil attributes have shown that the number of subsamples and sampling points influences mapping. However, there are no studies that investigated the influence of sampling or subsampling density on ECa maps. Therefore, this study verified the influence of ECa readings per sample point on the semivariance and kriging analysis. The data were collected from an area (2.5 ha) of coffee plants. One hundred sampling points were measured considering 20 readings each. 1, 5, 10, 15, and 20 sample point readings were tested. The influence of the number of readings per sampling point on the ECa mapping was determined using linear regression analysis at a significance level of 5\%. The results obtained showed that $\mathrm{ECa}$ readings per sampling point significantly influence ECa maps. In addition, they demonstrated that reducing the number of readings per sampling point increases prediction errors by kriging. Thus, ECa maps determined with the highest readings per sampling point were mostly accurate.
\end{abstract}

\section{INTRODUCTION}

Detecting spatial variability of soil attributes and determining management zones using soil apparent electrical conductivity (ECa) sensors have helped reduce cost attached to soil sampling (Stadler et al., 2015; Corwin \& Scudiero, 2020). This is because ECa presents reliable data of easy and fast measurements at a low cost (Corwin \& Scudiero, 2020). Furthermore, the research results indicate that ECa correlates with physical and chemical soil attributes (Moral et al., 2010; Valente et al., 2014; Bottega et al., 2015; Neely et al., 2016; Uribeetxebarria et al., 2018).

There are three types of ECa sensors based on the principles of electrical resistivity, electromagnetic induction, and reflectometry in the time domain (Corwin \& Lesch, 2005). ECa sensors that operate based on electrical resistivity and electromagnetic induction are widely used (Moral et al., 2010; Terrón et al., 2011). Both types of sensors generate readings that correlate with soil attributes and can be used to direct soil sampling and define management zones.

In the literature, there are studies in which ECa data survey was performed with portable sensors (Valente et al., 2012; Costa et al., 2014; Medeiros et al., 2016) and sensors embedded in ground vehicles (Peralta et al., 2013; Serrano et al., 2014; Pedrera-Parrilla et al., 2016). There is a difference in sampling densities used in the surveys with portable and onboard sensors. Thus, the results obtained may be different pertaining to the spatial variability of ECa.

To measure a variable associated with the soil-plant system, it is necessary to define the number of readings considered to represent the value of the variable at each point. Studies have been carried out to evaluate the influence of the number of sampling points on the preparation of maps of soil attributes (Souza et al., 2014). In the case of $\mathrm{ECa}$, research has been carried out to verify the influence of soil moisture on the magnitude of the values and on the spatial variability and temporal stability of the

\footnotetext{
${ }^{1}$ Universidade Federal Rural de Pernambuco, Departamento de Engenharia Agrícola/ Recife - PE, Brasil.

${ }^{2}$ Universidade Federal de Viçosa, Departamento de Engenharia Agrícola/ Viçosa - MG, Brasil.

${ }^{3}$ Universidade de São Paulo/ Escola Superior de Agricultura "Luiz de Queiroz", Departamento de Solos e Nutrição de Plantas/ Piracicaba - SP, Brasil.
} 
variable (Molin \& Faulin, 2013; Serrano et al., 2013; Costa et al., 2014).

The study conducted by Pias et al. (2018) showed that, as well as the number of sample points, the number of sub-samples or readings/measurements per sample point should be considered in spatial data analysis. The results obtained indicate that the greater the number of subsamples per sample point, the greater the accuracy of the map generated.

The local variability of a given attribute is equivalent, or even higher, considering the global spatial variability in a given area. Thus, it is essential to repeat the readings of a given variable when a sensor is in use, as it is an equipment with low cost in data acquisition and high operational capacity, it is possible to increase the data acquisition rate without increasing so much the cost of its use and thus better represent the local and spatial variability of this attribute. It is expected that the map generated will exhibit global accuracy and, consequently, an adequate intervention. Therefore, this study was carried out to verify whether the number of readings per sample point influences the spatial pattern of the ECa of the soil determined using a portable sensor.

\section{MATERIAL AND METHODS}

The soil ECa sensor used for data acquisition was developed based on the principle of resistivity measured by electrodes spaced at $0.3 \mathrm{~m}$ and arranged according to the Wenner matrix. The sensor was developed using a BeagleBone Black (BBB) single-board computer with Debian 7.9, connected to a 7" LCD (Liquid Crystal Display) Cape touch screen manufactured by 4D Systems (Minchinbury, Australia), an electronic circuit for signal conversion and amplification, an electronic circuit to determine the potential difference caused by the soil, and a conditioning circuit to adjust the signal between 0 and 1.8 V. A global navigation satellite system (GNSS) module, a model of ultimate global positioning system (GPS) manufactured by Adafruit (Adafruit Technologies, NY), was connected to the $\mathrm{BBB}$ to register the coordinates of the points where the readings were determined. The developed sensor was operated using $\mathrm{C}++$ with the integrated development environment of Qt Creator version 5.11.1.

The ECa data and their respective coordinates were obtained in an Arabica coffee crop field of $\sim 2.5$ ha in Paula Cândido - MG. As shown in Figure 1, 100 sampling points were distributed, following systematized sampling that references the crop rows of the coffee crops. Thus, the sampling density adopted was 40 points per hectare. Within a radius of $3 \mathrm{~m}$ from each sampling point, 20 readings of ECa were randomly selected, which generated a database with 2,000 readings. The Shapiro-Wilk test was used to analyze the distribution of these data.

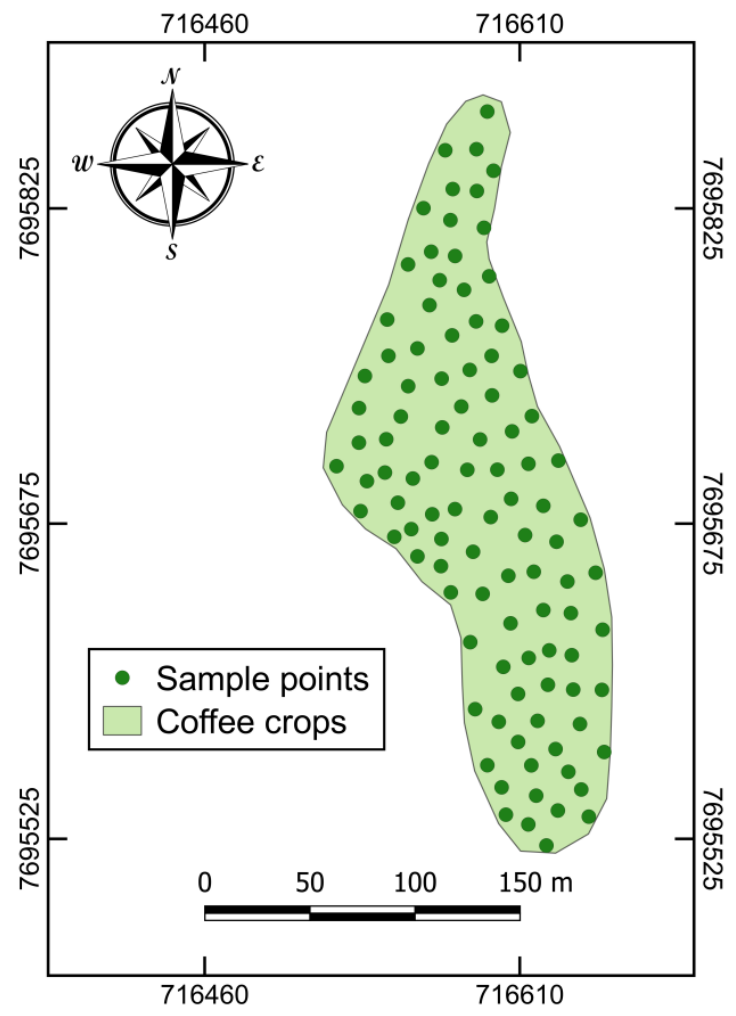

FIGURE 1. Distribution map of the sample points in the experimental area.

In each of the 100 sample points, with 20 readings, the standard deviation of the apparent electrical conductivity measurements was calculated. Thus, using ordinary kriging, the map of the standard deviation of the studied variable was prepared. Thus, it was possible to measure the variability at a local level in the study area.

The number of readings per sample point to determine the ECa with an error of up to $10 \%$ around the mean was obtained using the methodology presented by Pias et al. (2018). The below equation was proposed by Petersen and Calvin (1965) (Equation 1).

$$
n=\frac{t_{\alpha} x S^{2}}{D^{2}}
$$


Where:

$n$ is the number of readings per sample point,

$t_{\alpha}$ is the tabulated value of $t$ for significance $(\alpha)$ and degrees of freedom used to estimate the sample variance,

$S$ is the standard deviation of the mean, and

$D$ is the mean value divided by the desired percentage error around the mean.

The verification of the effect caused by the readings to represent a sample unit was done based on the gradual reduction of the number of readings. The number of readings used to represent sample points was reduced using the function "stratified" of the library "splitstackshape" (Mahto, 2019) of R language, version 3.4.0 (R Core Team, 2019), in the RStudio environment (developed by RStudio Inc, Boston, USA). This function performs stratified sampling where it randomly selects a desired number of samples within a given sample group contained in a dataset. In this case, the sample group was the one in which all the readings belonged to the same sample point.

After the reduction process, the reading numbers used to represent each sample point were $1,5,10,15$, and 20. The data sets resulting from the stratified sampling were subjected to outlier analysis to remove discrepant observations. The discrepant readings were those that were higher than the mean plus three times the standard deviation and lower than the mean minus three times the standard deviation (Barnett \& Lewis, 1994). After analyzing the discrepant data, the average values were obtained from the remaining readings for stratified sampling and were used to represent their respective sample points. Moreover, at each sample point, the standard deviation of the readings was calculated.

With the data sets pertaining to the reduction in the number of readings per sample point, semivariance and kriging analysis were performed using the GS+ software, version 10 (Gamma Design Software, LLC, Plainwell, MI, USA). Thus, the maps of soil ECa were prepared using sample points represented by one reading, which is the average of 5, 10, 15, and 20 readings. Each map obtained was classified into five classes based on the fuzzy K-means algorithm. The classified maps were compared with each other based on the Kappa concordance index. The map of ECa obtained with sample points represented by 20 readings was considered as a reference. To verify if there was statistical equality, the Kappa agreement indexes obtained for the maps were compared among themselves using the $\mathrm{Z}$ test at a significance level of 5\%. The number of readings per sample point on the spatial pattern of ECa was verified based on the statistical distinction between the Kappa indexes obtained from the comparison among the evaluated maps.

\section{RESULTS AND DISCUSSION}

The database with all the readings obtained in this study presented a normal distribution using the ShapiroWilk test. The semivariance analysis of the data generated the parameters of the theoretical models listed in Table 1. The fitted models were exponential and spherical. However, the data set in which five readings represented each sample point exhibited spherical behavior. The other sets fitted better to the exponential model. The spherical and exponential models prevail in soil science studies in Brazil (Molin \& Faulin, 2013). According to Silva et al. (2013), the spherical and exponential models mainly prevail as soil attributes present strong self-correlation at smaller distances. The increase in the number of readings per sample point caused an increase in the proportion between the contribution $(\mathrm{C})$ and plateau $(\mathrm{C} 0+\mathrm{C})$ and a reduction in the number of errors based on the estimation done using kriging during cross-validation (Table 1). This implies greater accuracy of the maps generated, as verified by Pias et al. (2018) in a study on the influence of the number of subsamples on the preparation of the maps of the soil resistance to penetration. Increasing the number of readings per sample point helps detail the representation of the local variability, which tends to smooth the variability between the sample points. According to the methodology of Pias et al. (2018), to obtain a $10 \%$ error based on the mean of ECa in the area where the present study was performed, it would be necessary to perform 30 readings per sample point. Therefore, additional 10 readings would be required.

TABLE 1. Parameters obtained in the semivariance analysis of soil ECa data.

\begin{tabular}{|c|c|c|c|c|c|c|c|}
\hline \multirow[b]{2}{*}{ Variable } & \multicolumn{6}{|c|}{ Semivariogram parameters } & \multirow[b]{2}{*}{ EPVC3 } \\
\hline & Model & Range (m) & $(\mathrm{CO} /[\mathrm{CO}+\mathrm{C}])^{10}$ & $\begin{array}{c}\text { Proportion } \\
(\mathrm{C} /[\mathrm{CO}+\mathrm{C}])^{9}\end{array}$ & $\mathbf{R}^{2(\mathbf{1})}$ & SQR2 & \\
\hline ECa4 & Exponential & 104.7 & 0.418 & 0.582 & 0.96 & 0.119 & 1.715 \\
\hline $\mathrm{ECa}^{55}$ & Spherical & 209 & 0.415 & 0.585 & 0.99 & 0.042 & 1.448 \\
\hline $\mathrm{ECa}^{106}$ & Exponential & 235.2 & 0.307 & 0.693 & 0.99 & 0.032 & 1.201 \\
\hline $\mathrm{ECa}{ }^{157}$ & Exponential & 147.9 & 0.205 & 0.795 & 0.99 & 0.043 & 1.183 \\
\hline $\mathrm{ECa}^{208}$ & Exponential & 153.0 & 0.204 & 0.796 & 0.99 & 0.045 & 1.130 \\
\hline
\end{tabular}

${ }^{1}$ Coefficient of determination $/{ }^{2} \mathrm{Sum}$ of squares of residuals $/{ }^{3} \mathrm{Standard}$ error in cross-validation $/{ }^{4} \mathrm{ECa}$ determined with one reading $/{ }^{5} \mathrm{ECa}$ determined with five readings $/{ }^{6} \mathrm{ECa}$ determined with ten readings $/{ }^{7} \mathrm{ECa}$ determined with fifteen readings $/{ }^{8} \mathrm{ECa}$ determined with twenty readings $/{ }^{9}$ Relation between contribution and plateau $/{ }^{10}$ Relation between nugget effect and plateau. 
The reduction in the number of readings per sample point also caused an increase in the error of the interpolation estimate. Moreover, this behavior was observed by Souza et al. (2014) and Nogueira Martins et al. (2019), who studied the effect of reducing the density of the sampling grid on spatial variability of soil attributes. As in the present study, Souza et al. (2014) found that with the reduction in the number of samples, the relationship between the nugget effect and the plateau (Table 1) gradually diminishes, which characterizes the structure of spatial dependence.

The results show that for $\mathrm{ECa}$, the number of readings per sample point plays a crucial role in obtaining maps with lower uncertainties. Therefore, in studies where the objective is to minimize the uncertainties of the maps generated for ECa, the density of the sampling grid, as reported by Souza et al. (2014) and Nogueira Martins et al. (2019), and the number of readings per sample point should be considered. Thus, the results indicate that there may be a relationship between sample and subsample densities (number of readings per sampling point) that may influence the elaboration of the maps. In the case of ECa, this possible relationship should be better studied.
According to the classification proposed by Cambardella et al. (1994), the surveys carried out with 1, 5, and 10 readings per sampling point showed moderate spatial dependence, while the surveys carried out with 15 and 20 readings per sampling point showed strong spatial dependence. This behavior indicates a decrease in spatial dependence when the number of readings per sampling point is reduced.

The maps of the standard deviation of ECa and ECa generated with different numbers of readings per sample point are shown in Figure 2. The spatial distribution of the map of the standard deviation of the variable studied exhibits similarities with the spatial distribution of the other maps. It can be seen that where the ECa values were higher, there was a high variability of this variable and vice versa. This indicates that the points with higher values of ECa readings would require a more number of readings for a better representation. Regarding the maps obtained with different numbers of readings per sample point, it can be seen that although there was an increase in the prediction error with a decrease in the number of readings per sample point, it is possible to verify that there is a similarity between the spatial patterns of the maps generated (Figure 2).

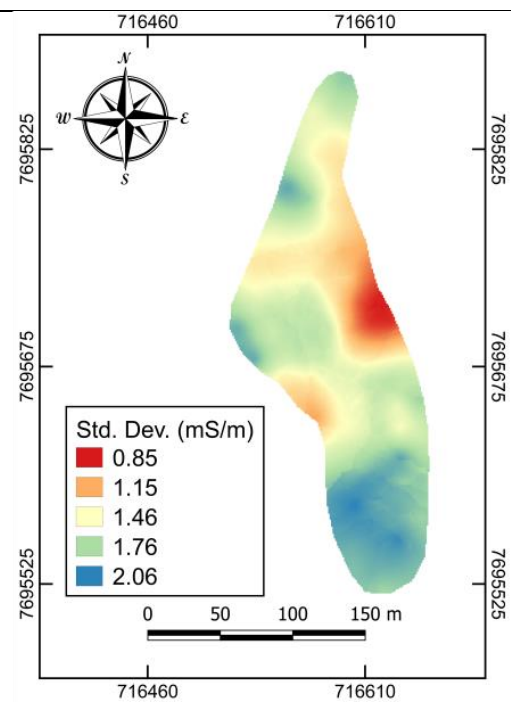

(A)

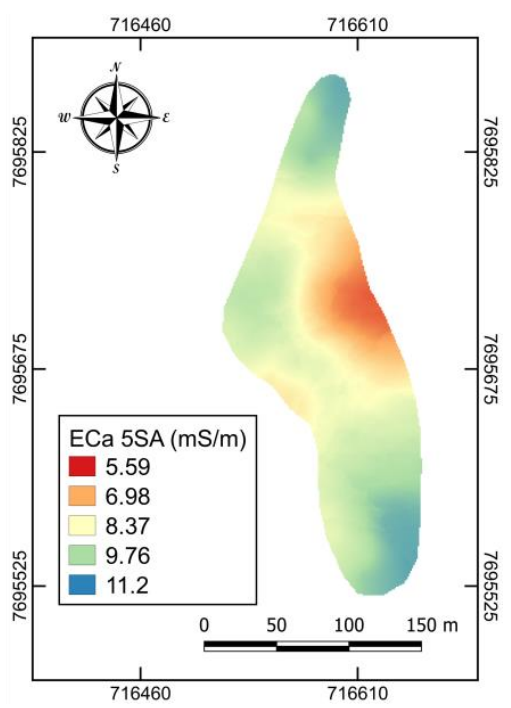

(C)

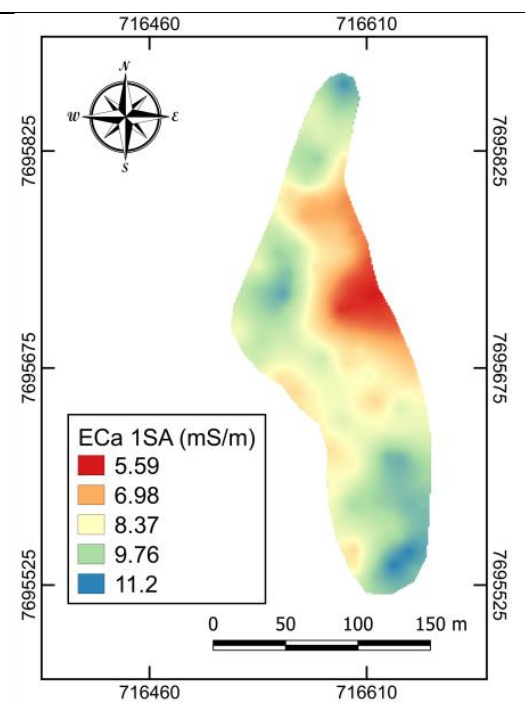

(B)

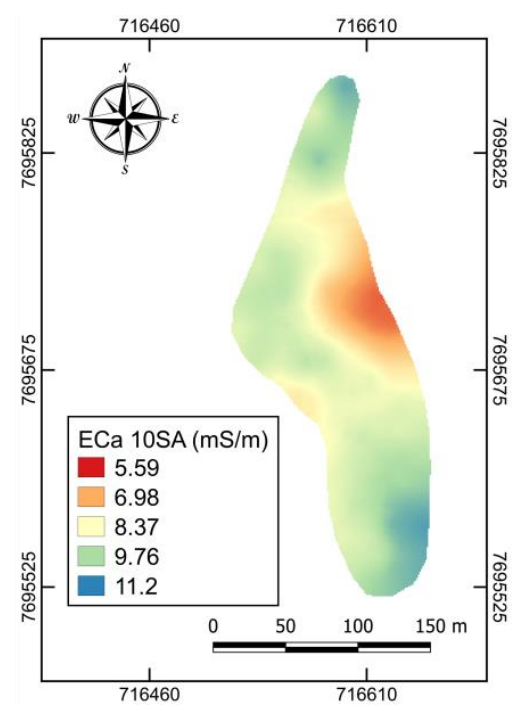

(D) 


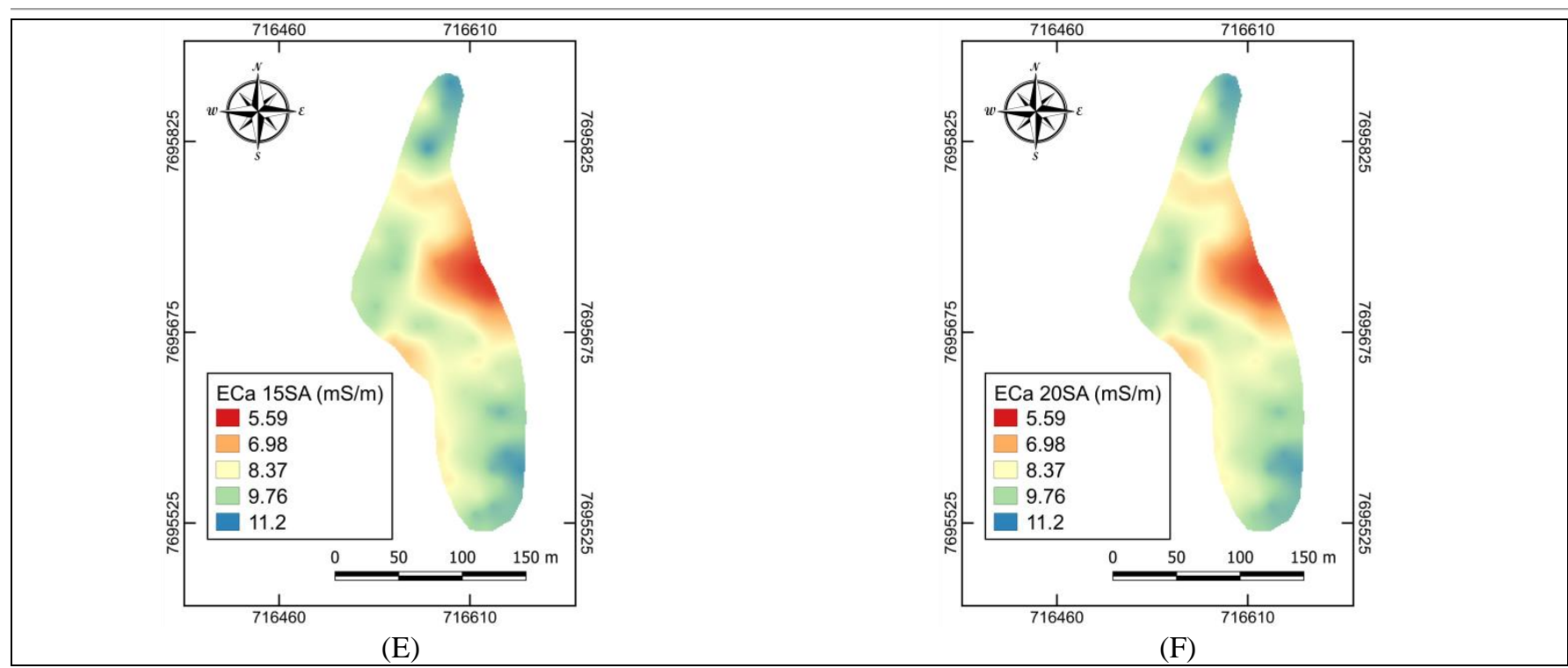

FIGURE 2. Comparison between the maps of soil ECa generated with a database containing different readings per sample point. (A) Map of the standard deviation of ECa; (B) map generated with sample points represented based on 1 reading; (C) map generated with sample points represented by 5 readings; (D) map generated with sample points represented by 10 readings; (E) map generated with sample points represented by 15 readings; $(\mathrm{F})$ map generated with sample points represented by 20 readings.

The comparisons between the ECa maps generated with different numbers of readings per sample point are listed in Table 2. The Kappa agreement indices obtained indicate a reduction in the agreement between the maps as the number of readings per sample point decreased. This result indicates that the number of readings per sample point influenced the determination of the spatial pattern of ECa.

TABLE 2. Kappa agreement indices between soil ECa maps obtained with different numbers of readings per sample point.

\begin{tabular}{lccccc}
\hline \multicolumn{1}{c}{ Kappa } & ECa & ECa 5 & ECa 10 & ECa 15 & ECa 20 \\
\hline ECa1 & 1 & & & & \\
ECa 5 $^{2}$ & 0.51 & 1 & 1 & 1 & \\
ECa 10 $^{3}$ & 0.56 & 0.73 & 0.74 & $0.89 \mathrm{D}$ & 1 \\
ECa ${ }^{254}$ & 0.45 & 0.58 & $0.78 \mathrm{C}$ & \\
ECa & & &
\end{tabular}

All Kappa indices were significant at a $5 \%$ level based on the z-test. ${ }^{1} 1$ reading per sample point $/ 25$ readings per sample point $/{ }^{3} 10$ readings per sample point $/^{4} 15$ readings per sample point $/{ }^{5} 20$ readings per sample point. Kappa indices with distinct letters in the last row of the table differed from each other at a $5 \%$ significance level.

\section{CONCLUSIONS}

As the number of readings used to represent a sample point increases, the error in the kriging estimation tends to decrease.

The highest error in interpolation based on kriging was obtained when the sample points were represented by one reading of soil ECa.

The observed spatial dependence was reduced when the number of readings per sample point was reduced.

The spatial patterns of the soil ECa maps generated with sample points, which are represented by different readings, had similarities among them.

The number of readings per sample point of soil ECa significantly influenced the mapping process of the variable.

\section{ACKNOWLEDGMENTS}

The authors thank the National Council for Scientific and Technological Development, the Coordination for the Improvement of Higher Education Personnel, and the Research Support Foundation of the State of Minas Gerais for the financial support.

\section{REFERENCES}

Barnett V, Lewis T (1994) Outliers in statistical data. John Wiley \& Sons, 3 rd ed. 608p.

Bottega EL, Queiroz DM de, Santos NT, Pinto F de A de C, Souza CMA de (2015) Correlation between apparent electrical conductivity and chemical and physical attributes of a Rhodic Hapludox. Comunicata Scientiae 6(2): 134-142. Doi: https://doi.org/10.14295/cs.v6i2.354

Cambardella CA, Moorman TB, Novak JM, Parkin TB, Karlen DL, Turco RF, Konopka AE (1994) Field-scale variability of soil properties in Central Iowa Soils. Soil Science Society of America Journal 58(5). Doi: https://doi.org/10.2136/sssaj1994.03615995005800050033x

Corwin DL, Lesch SM (2005) Apparent soil electrical conductivity measurements in agriculture. Computers and Electronics in Agriculture 46(1-3). Doi: https://doi.org/10.1016/j.compag.2004.10.005

Corwin DL, Scudiero E (2020) Field-scale apparent soil electrical conductivity. Soil Science Society of America Journal 84(5). Doi: https://doi.org/10.1002/saj2.20153 
Costa MM, Queiroz DM de, Pinto FDA de C, Reis EF dos, Santos NT (2014) Moisture content effect in the relationship between apparent electrical conductivity and soil attributes. Acta Scientiarum. Agronomy 36(4). Doi: https://doi.org/10.4025/actasciagron.v36i4.18342

Mahto A (2019) Splitstackshape: stack and reshape datasets after splitting concatenated values. $\mathrm{R}$ package version 1.4.8. Available: https://CRAN.Rproject.org/package=splitstackshape. Accessed: Maio 10, 2019.

Medeiros WN, Queiroz DM de, Valente DSM, Pinto F de A de C, Melo CAD (2016) The temporal stability of the variability in apparent soil electrical conductivity. Bioscience Journal 32(1). Doi: https://doi.org/10.14393/BJ-v32n1a2016-26287

Molin JP, Faulin GDC (2013) Spatial and temporal variability of soil electrical conductivity related to soil moisture. Scientia Agricola 70(1). Doi: https://doi.org/10.1590/S0103-90162013000100001

Moral FJ, Terrón JM, Silva JRM da (2010) Delineation of management zones using mobile measurements of soil apparent electrical conductivity and multivariate geostatistical techniques. Soil and Tillage Research 106(2). Doi: https://doi.org/10.1016/j.still.2009.12.002

Neely HL, Morgan CLS, Hallmark CT, McInnes KJ, Molling CC (2016) Apparent electrical conductivity response to spatially variable vertisol properties. Geoderma 263. Doi:

https://doi.org/10.1016/j.geoderma.2015.08.040

Nogueira Martins R, Ferreira Lima dos Santos F, Moura Araújo G de, Arruda Viana L de, Fim Rosas JT (2019) Accuracy assessments of stochastic and deterministic interpolation methods in estimating soil attributes spatial variability. Communications in Soil Science and Plant Analysis 50(20). Doi: https://doi.org/10.1080/00103624.2019.1670836

Pedrera-Parrilla A, Van De Vijver E, Van Meirvenne M, Espejo-Pérez A J, Giráldez JV, Vanderlinden K (2016) Apparent electrical conductivity measurements in an olive orchard under wet and dry soil conditions: significance for clay and soil water content mapping. Precision Agriculture 17(5). Doi: https://doi.org/10.1007/s11119-016-9435-z

Peralta NR, Costa JL, Balzarini M, Angelini H (2013) Delineation of management zones with measurements of soil apparent electrical conductivity in the southeastern pampas. Canadian Journal of Soil Science 93(2). Doi: https://doi.org/10.4141/cjss2012-022

Pias OH de C, Cherubin MR, Basso CJ, Santi AL, Molin J P, Bayer C (2018) Soil penetration resistance mapping quality: effect of the number of subsamples. Acta Scientiarum. Agronomy 40(1). Doi: https://doi.org/10.4025/actasciagron.v40i1.34989
R Core Team (2019) R: A language and environment for statistical computing. R Foundation for Statistical Computing, Vienna, Austria. 2019. Available: https://www.R-project.org/. Accessed Maio 10, 2019.

Serrano JM, Shahidian S, Marques da Silva JR (2013) Apparent electrical conductivity in dry versus wet soil conditions in a shallow soil. Precision Agriculture 14(1). Doi: https://doi.org/10.1007/s11119-012-9281-6

Serrano J, Shahidian S, Silva J (2014) Spatial and temporal patterns of apparent electrical conductivity: DUALEM vs. Veris sensors for monitoring soil properties. Sensors 14(6). Doi: https://doi.org/10.3390/s140610024

Silva S, Lima JS, Bottega E (2013) Yield mapping of Arabic coffee and their relationship with plant nutritional status. Journal of Soil Science and Plant Nutrition, (ahead). Doi: https://doi.org/10.4067/S0718-95162013005000044

Souza ZM de, Souza GS de, Marques Júnior J, Pereira GT (2014) Número de amostras na análise geoestatística e na krigagem de mapas de atributos do solo. Ciência Rural 44(2). Doi: https://doi.org/10.1590/S010384782014000200011

Stadler A, Rudolph S, Kupisch M, Langensiepen M, van der Kruk J, Ewert F (2015) Quantifying the effects of soil variability on crop growth using apparent soil electrical conductivity measurements. European Journal of Agronomy 64: 8-20. Doi:

https://doi.org/10.1016/j.eja.2014.12.004

Terrón JM, Marques da Silva JR, Moral FJ, García-Ferrer A (2011) Soil apparent electrical conductivity and geographically weighted regression for mapping soil. Precision Agriculture 12(5). Doi: https://doi.org/10.1007/s11119-011-9218-5

Uribeetxebarria A, Arnó J, Escolà A, Martínez-Casasnovas JA (2018) Apparent electrical conductivity and multivariate analysis of soil properties to assess soil constraints in orchards affected by previous parcelling. Geoderma 319. Doi: https://doi.org/10.1016/j.geoderma.2018.01.008

Valente DSM, Queiroz DM de, Pinto F de A de C, Santos FL, Santos NT (2014) Spatial variability of apparent electrical conductivity and soil properties in a coffee production field. Engenharia Agrícola 34(6). Doi: https://doi.org/10.1590/S0100-69162014000600017

Valente DSM, Queiroz DM de, Pinto F de A de C, Santos NT, Santos FL (2012) The relationship between apparent soil electrical conductivity and soil properties. Revista Ciência Agronômica 43(4). Doi: https://doi.org/10.1590/S1806-66902012000400009 